\title{
Atividade antibacteriana de extratos de folhas de Montrichardia linifera (Arruda) Schott (Araceae)
}

MIRANDA, J.A.L.'; ROCHA, J.A.1,2; ARAÚJO, K.M..; QUELEMES, P.V.'; MAYO, S.J. ${ }^{3}$, ANDRADE, I.M.1*. - Universidade Federal do Piauí, UFPI, Campus de Parnaíba, Av. São Sebastião, $n^{\circ}$ 2819, Parnaíba, PI, CEP. 64202-020, 2 Universidade Federal do Maranhão Campus VII Av. Dr. José Anselmo, $n^{\circ}$ 2008, Bairro São Benedito - Codó-MA CEP 65400-000. ' Herbarium, Royal Botanic Gardens, Kew, Richmond TW9 3AE, UK, * Autor para correspondência: simonjosephmayo@gmail.com

RESUMO: O uso de plantas medicinais no tratamento de doenças é uma estratégia antiga utilizada por praticamente todas as populações do mundo, e, embora novos antibióticos tenham sido desenvolvidos para o controle de micro-organismos infecciosos, às vezes são ineficazes. Diversos extratos de plantas medicinais têm efeitos antimicrobianos, principalmente quando associados à antibióticos de uso clínico, representando alternativa terapêutica para doenças infecciosas. Montrichardia linifera, conhecida popularmente como aninga, é espécie macrófita, aquática emergente de hábito herbáceo, pertencente a família Araceae e ocorre em áreas alagáveis. A utilidade farmacológica desta espécie é diversificada tendo sido relatada como cicatrizante, antirreumático, antidiurético e expectorante. Devido à relevância no campo etnofarmacológico, ampla utilização na medicina popular e escassez de trabalhos relacionados à atividade antibacteriana desta espécie, objetivou-se com este trabalho avaliar a atividade antibacteriana de extratos alcoólicos de folhas de Montrichardia linifera, coletadas na margem do rio Igaraçu, Parnaíba-PI. O extrato foi testado em oito cepas de bactérias: Staphylococcus aureus, Staphylococcus epidermidis, Enterococcus faecalis, Escherichia coli, Klebsiella pneumoniae e Pseudomonas aeruginosa. Foram utilizadas as técnicas de verificação da formação de halos de inibição e determinação das concentrações inibitórias e bactericidas mínimas. Os testes antibacterianos evidenciaram como principais resultados que o extrato metanólico seco (EMS), extrato metanólico fresco (EMF), e o extrato etanólico seco (EES), apresentaram ação antibacteriana, enquanto o extrato etanólico fresco (EEF) não apresentou atividade para as bactérias testadas. O EMS foi o mais eficiente, inibindo o crescimento bacteriano na concentração de $200 \mu \mathrm{g} / \mathrm{mL}$ para E. faecalis, $400 \mu \mathrm{g} / \mathrm{mL}$ para S. aureus, $400 \mu \mathrm{g} /$ $\mathrm{mL}$ para $S$. epidermidis e $2.000 \mu \mathrm{g} / \mathrm{mL}$ para $P$. aeruginosa. O EMF obteve CIM de $2.000 \mu \mathrm{g} / \mathrm{mL}$ para E. faecalis e EES obteve CIM de $250 \mu \mathrm{g} / \mathrm{mL}$ para E. faecalis. Os resultados demonstraram que $M$. linifera constitui fonte eficiente de compostos bioativos antibacterianos. Os estudos sobre as propriedades farmacológicas de plantas da família Araceae são escassos, e os resultados deste trabalho são pioneiros em relação a atividade antibacteriana desta espécie.

Palavras-chave: Araceae, bioatividade, extratos alcoólicos, atividade antibacteriana.

\begin{abstract}
Antibacterial activity of leaf extracts of Montrichardia linifera (Arruda) Schott (Araceae). For a long time, medicinal herbs have been used in the treatment of diseases by almost all populations in the world, and although new antibiotics have been developed for the control of infectious micro-organisms, they are sometimes ineffective. Many herbal extracts have antimicrobial effects and represent a potential alternative therapy for infectious diseases, especially when associated with the clinical use of antibiotics. The Montrichardia linifera, popularly known as Aninga, is a robust, herbaceous, emergent aquatic macrophyte belonging to the Araceae family, appearing along rivers and stream margins in the tropical America. The pharmacological application of this species are several ones, having been reported to own a healing, antirheumatic, anti-diuretic and expectorant effect. Due to the relevance in the ethnopharmacological field, the spread use in popular medicine and the few researches related to the antibacterial activity of this specie, the study aimed to evaluate the antibacterial activity of alcoholic leaf extracts of plants of Montrichardia linifera collected along
\end{abstract}

Rev. Bras. PI. Med., Campinas, v.17, n.4, supl. III, p.1142-1149, 2015. 
the margins of Rio Igaraçu, Parnaíba, Piauí, Brazil. The extract was tested in eight strains of ATCC bacterial standards: Staphylococcus aureus, Staphylococcus epidermidis, Enterococcus faecalis, Escherichia coli, Klebsiella pneumonia and Pseudomonas aeruginosa. The verification techniques used were the formation of inhibition halos, and the determination of minimum inhibitory and bactericidal concentrations (MIC). The antibacterial tests showed, as main results, that dried methanol extract (EMS), fresh methanol extract (EMF) and dry ethanol extract (EES) exhibited antibacterial activity, while the fresh ethanol extract (EEF) was inactive against the tested bacteria. The EMS was the most efficient one, inhibiting bacterial growth at a concentration of $200 \mu \mathrm{g} / \mathrm{mL}$ for E. faecalis, $400 \mu \mathrm{g} / \mathrm{mL}$ for $S$. aureus $400 \mu \mathrm{g} / \mathrm{mL}$ for $S$. epidermidis and 2.000 $\mu \mathrm{g} / \mathrm{mL}$ for $P$. aeruginosa. The EMF obtained a MIC of $2.000 \mu \mathrm{g} / \mathrm{mL}$ for $E$. faecalis and EES obtained a MIC of $250 \mu \mathrm{g} / \mathrm{mL}$ for $E$. faecalis. The results showed that $M$. linifera is an efficient source of bioactive antibacterial compounds. Studies about the pharmacological properties of plants of the family Araceae are scarce, and the results of this work are pioneer in regard to the antibacterial activity of this species.

Keywords: Araceae, bioactivity, alcoholic extracts, antibacterial activity.

\section{INTRODUÇÃO}

Estima-se que existam 250.000 a 500.000 espécies de plantas na Terra e, porcentagem relativamente pequena (cerca de 1 a $10 \%$ ) é utilizada como alimentos por seres humanos e outras espécies animais, possivelmente porcentagem maior seja utilizada para fins medicinais (Cowan, 1999), desempenhado papel significativo na manutenção da saúde humana e melhoria na qualidade de vida (Haque et al., 2014).

As plantas medicinais têm sido utilizadas desde os primórdios da civilização pelo ser humano na prevenção e/ou na cura de doenças, sendo este hábito culturalmente difundido de geração para geração (Lopes et al., 2010; Santos et al., 2012; Feijó et al., 2012).

A Terapêutica caracterizada pelo uso de plantas medicinais em suas diferentes formas farmacêuticas é chamada de fitoterapia sendo bastante utilizada de forma eficaz em atendimento primário a saúde, com finalidade preventiva ou curativa de patologias (Bettega et al., 2011; Sousa et al., 2011; Bruning et al., 2012). Estima-se que $75-80 \%$ de toda a população utilize esta prática, principalmente em países em desenvolvimento onde deve haver cuidados primários de saúde, maior aceitabilidade cultural e acessibilidade ao tratamento, além da segurança terapêutica, em virtude da melhor compatibilidade com o corpo humano e a efeitos colaterais menos (Parekh et al., 2005; Roy et al., 2013).

Os compostos advindos das plantas medicinais capazes de inibir o crescimento de patógenos ou matá-los, além de apresentar toxicidade mínima para as células hospedeiras são consideradas candidatas para o desenvolvimento de novos antimicrobianos (Askari et al., 2012). Estes compostos são metabólitos secundários, grupo diversificado de moléculas que possuem atividades biológicas envolvidas nos mecanismos de adaptação da planta a seu meio e não apresentam funções diretamente relacionadas ao crescimento e desenvolvimento da planta, como é visto nos metabolitos primários. Contudo, na maioria das vezes, apresentam imensa atividade farmacológica de interesse ao ser humano (Dash et al., 2011; Pereira \& Cardoso, 2012).

Montrichardia linifera (Arruda) Schott (Figura 1), conhecida como Aninga, Aninguaçu e Aningaíba (Medina, 1959; Pulle \& Lanjouw, 1968; Silva et al., 2013), pertence a família Araceae, monocotiledôneas herbáceas, constituída de nove subfamílias, incluindo 117 gêneros e aproximadamente 3.373 espécies (Haigh et al., 2009). M. linifera é uma das duas espécies de Montrichardia, ocorre ao longo de margens de rios, nas regiões tropicais (Mayo et al., 1997); nativa e não endêmica do Brasil, podendo ser encontrada na Amazônia, Caatinga e Mata Atlântica, com representação nas regiões Norte, Nordeste e Sudeste do Brasil (Coelho, 2013). É caracterizada por apresentar 4-8 $\mathrm{m}$ de altura, haste com coroa terminal com folhas cordado-sagitadas, pecíolo longo, ereto e lenhoso, inflorescência do tipo espádice de cor branca amarelada, e infrutescência de coloração verde-escuro que se assemelha ao abacaxi. A forma da folha, número de veias secundárias em cada lado do lobo anterior da folha e a forma do sinus entre os lobos posteriores e presença de tricomas no caule são caracteres utilizados para diferenciar $M$. linifera de M. arborescens (Silva et al., 2012).

M. linifera possui tradição etnofarmacológica no Brasil (Amarante et al., 2010), apesar de ser conhecida como tóxica em humanos. A seiva causa queimaduras, erupções e manchas na pele e, em contato com os olhos, pode causar cegueira (Martins et al., 2005; Amarante et al., 2011b). Paradoxalmente, é utilizada na medicina tradicional

Rev. Bras. Pl. Med., Campinas, v.17, n.4, supl. III, p.1142-1149, 2015. 
como cicatrizante, antirreumática, antidiurética e expectorante (Plowman, 1969; Amorozo \& Gely, 1988; Lins, 1994; Amarante et al., 2011a), além do chá de folha senescente ser utilizado para o tratamento de doenças no fígado (Amarante et al., 2011a).

Devido à relevância no campo etnofarmacológico e ampla utilização na medicina popular, M. linifera tem importância como alvo de pesquisas com intuito de desvendar suas atividades biológicas. Contudo, várias atividades desta planta ainda não foram elucidadas, necessitando aprofundamento em estudos e compreensão dessas atividades.

A escassez de trabalhos relacionados à atividade antibacteriana de $M$. linifera, aliada ao aumento de resistência bacteriana a antibióticos utilizados na prática clínica, acarretando aumento das taxas de morbi-mortalidade na população, torna a avaliação de atividade antibacteriana utilizando extratos alcoólicos de folhas de $M$. linifera, portanto, relevante e promissora, tendo em vista que outras espécies da família Araceae apresentam atividade bacteriana (Alocasia decipiens, Colocasia esculenta, Lagendra ovata, Philodendron bipinnatifidum Philodendron amurense, Pistia stratiotes L. Epipermnum aureum, Alocasia indica, Typhonium trilobatum, Pothos aurea, e Scindapsus officinales) (Kubde et al. 2010; Santos, 2011; Khan et al., 2011; Roy et al., 2013; Saswati et al., 2013).

Neste contexto, o objetivo do trabalho foi avaliar o potencial antibacteriano de extratos etanólicos de folha de Montrichardia linifera coletadas no município de Parnaíba, Piauí.

\section{MATERIAL E MÉTODOS \\ Coleta e Identificação do Material Botânico \\ Folhas de Montrichardia linifera foram} coletadas em abril de 2013 na margem do rio Igaraçu $\left(02^{\circ} 58^{\prime} 57.0^{\prime \prime} \mathrm{S}\right.$ e $\left.041^{\circ} 46^{\prime} 21.4^{\prime \prime} \mathrm{W}\right)$, município de Parnaíba, Piauí, Brasil. Também foram coletadas amostras para registro em herbário. As amostras foram coletadas seguindo metodologia de campo de Fidalgo \& Bononi (1989) e identificadas pela Profa. Dra. Ivanilza Moreira de Andrade. A exsicata encontra-se depositada no herbário Delta do Parnaíba (HDELTA) da Universidade Federal do Piauí (UFPI), Campus Parnaíba, voucher no. 0285.

\section{Preparo da Planta in natura}

As folhas de Montrichardia linifera Arruda (Schott) passaram por um processo de limpeza, utilizando água destilada. Posteriormente, uma parte foi mantida in natura e a outra foi desidratada em estufa a $40{ }^{\circ} \mathrm{C}$. As duas amostras foram trituradas em moinho de facas, conforme Araújo et al. (2014). A amostra que passou pelo processo de secagem é denominada amostra seca, e outra que não passou pela secagem foi chamada amostra fresca.

\section{Obtenção do Extrato Bruto das folhas}

Foram utilizados dois solventes de extração, o metanol e o etanol, segundo Parekh et al. (2005). Foram pesadas duas porções de 10 gramas de material vegetal seco para a extração com metanol e etanol, utilizando $100 \mathrm{~mL}$ de cada solvente. Duas porções de 10 gramas de

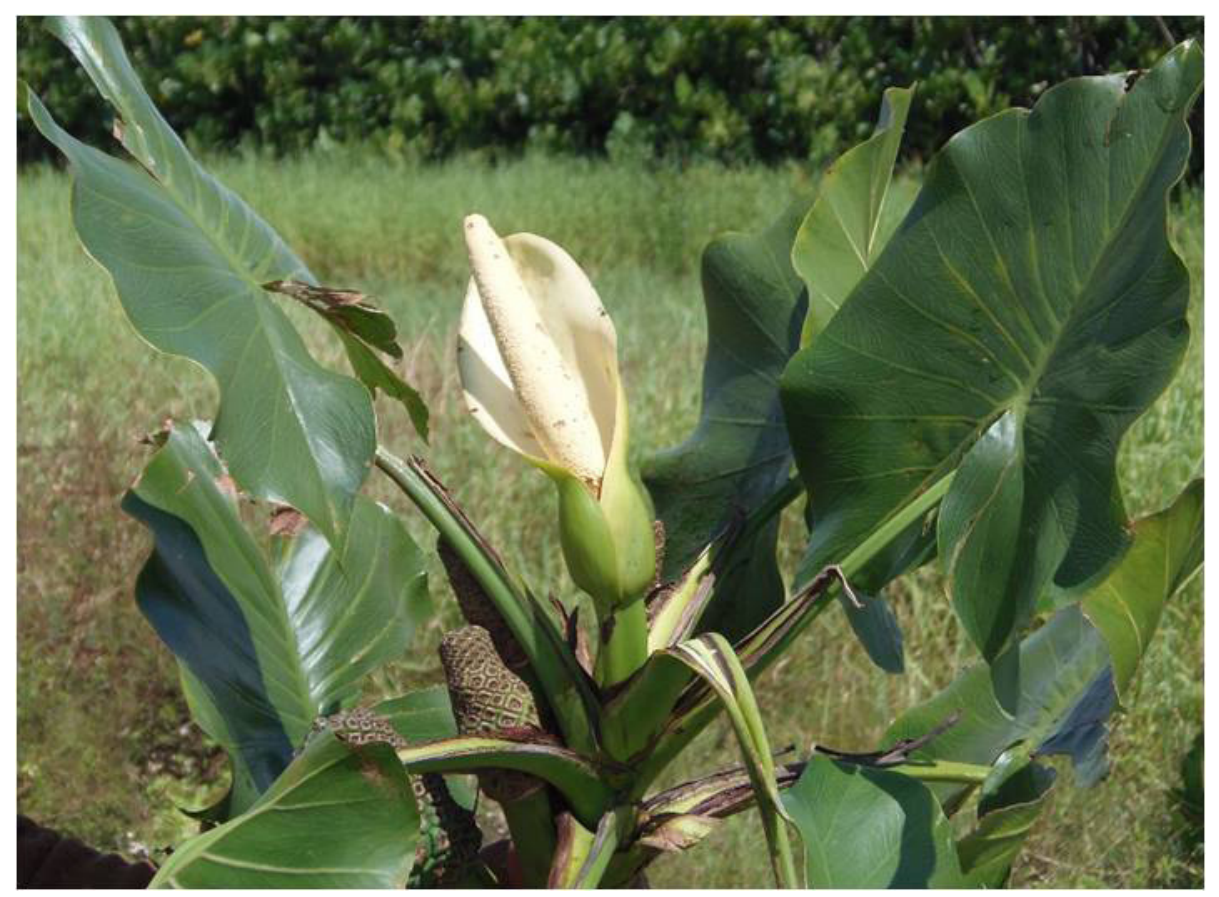

FIGURA 1. Montrichardia linifera (Arruda) Schott: aspecto geral da planta.

Rev. Bras. PI. Med., Campinas, v.17, n.4, supl. III, p.1142-1149, 2015. 
material vegetal fresco foram também pesadas para proceder a extração com os dois solventes, metanol e etanol, cada com $100 \mathrm{~mL}$. As amostras foram submetidas à agitação por 24 horas em uma mesa agitadora sem aquecimento, posteriormente filtradas com uma bomba à vácuo com o auxílio de um funil de Bucher e papel filtro $n^{0} 15$, e armazenadas em frascos âmbar à $4^{\circ} \mathrm{C}$.

Ao todo, foram obtidos quatro diferentes extratos das folhas da M. linifera: extrato metanol seco (EMS), extrato metanol fresco (EMF), extrato etanol seco (EES) e extrato etanol fresco (EEF).

Para a realização dos testes antimicrobianos, foram utilizados extratos concentrados para evitar a interferência do solvente. A partir do concentrado, pesou-se $20 \mathrm{mg}$ de cada um dos extratos e diluídos em $1 \mathrm{~mL}$ de Dimetilsulfóxido (DMSO) a 10\% (v/v), originando uma solução de $20 \mathrm{mg} / \mathrm{mL}$. Por fim, os extratos foram esterilizados por meio do uso de membrana poliestersulfônica (TPP) de 0,22 $\mu \mathrm{m}$.

\section{Ensaio Antibacteriano \\ As linhagens bacterianas e condições de crescimento}

As linhagens de bactérias utilizadas neste estudo foram, quatro Gram-negativas: Escherichia coli ATCC 25922, Escherichia coli ATCC 35218, Pseudomonas aueraginosa ATCC 27853, Klebsiella pneumoniae ATCC 700603; e quatro Gram-positivas: Staphylococccus aureus ATCC 25923, Staphylococccus aureus ATCC 29213, Staphylococcus epidermidis ATCC 12228, Enterococcus faecalis ATCC 29212.

Para preparação do inoculo bacteriano, as bactérias foram semeadas em placas de Petri com dimensões $90 \times 15 \mathrm{~mm}$, com meio ágar Mueller-Hinton (DIFCO ${ }^{\circledR}$ ) durante 24 horas a uma temperatura de $37^{\circ} \mathrm{C}$, em condições aeróbicas. Após esse período de incubação, foram coletadas colônias isoladas com auxílio de alça de platina, e transferidas para tubos com solução salina estéril $[\mathrm{NaCl} 0,85 \%,(\mathrm{p} / \mathrm{v})]$ até que se obtivesse turbidez correspondente à escala de McFarland 0,5 (aproximadamente $1 \times 10^{8} \mathrm{UFC} / \mathrm{mL}$ ) (CLSI, 2003a). A partir dessa suspensão foram realizados os testes antibacterianos. Toda a manipulação bacteriana foi realizada em condições assépticas de câmara de fluxo laminar.

\section{Método de Difusão em ágar (MDA)}

Este teste foi realizado de acordo com Maia-Araújo et al. (2011) e CLSI (2003b), com algumas adaptações. Primeiramente, mergulhouse um swab de algodão estéril em um tubo contendo a suspensão bacteriana ajustada à turbidez de 0,5 da escala McFarland. À superfície de uma placa de ágar Mueller-Hinton (com aproximadamente $4 \mathrm{~mm}$ de espessura) foi inoculado cada micro-organismo esfregando-se o swab em toda a superfície estéril do ágar. Em seguida, foram realizadas perfurações no ágar com $6 \mathrm{~mm}$ de diâmetro nas quais foram depositadas alíquotas de $60 \mu \mathrm{L}$ de cada extrato nas concentrações de 5 e $10 \mathrm{mg} / \mathrm{mL}$. O experimento foi realizado em triplicata, tendo como controle, uma solução contendo de DMSO a 10\% (veículo utilizado para a diluição dos extratos). As placas foram então encubadas a $37^{\circ} \mathrm{C}$, em condições aeróbicas. Após 24 horas, foram medidos, com auxílio de paquímetro digital, os diâmetros dos halos de inibição promovidos pelos extratos.

\section{Determinação da Concentração Inibitória Mínima (CIM) \\ Para determinação da Concentração} Inibitória Mínima (CIM) foram utilizadas placas de microdiluição estéreis com 96 poços de fundo chato nas quais foram realizadas diluições seriada de razão 2 em caldo Mueller-Hinton. Ao final do processo, as concentrações dos extratos variaram de 250 a $2000 \mu \mathrm{g} / \mathrm{mL}$ e os poços continham um inoculo de $5 \times 10^{5} \mathrm{UFC} / \mathrm{mL}$ (CLSI, 2003a). Foram estabelecidos dois controles positivos (um de viabilidade bacteriana e outro com DMSO) e dois negativos (um de esterilidade do meio e outro de esterilidade do extrato). O mesmo procedimento foi utilizado para a determinação das CIMs dos antibióticos padrões efetivos contra as bactérias testadas: Oxacilina para as Gram-positivas e Meropenen paras as Gram-negativas. Todos os experimentos foram realizados em triplicata.

As placas foram, então, incubadas sob condições aeróbicas a $37^{\circ} \mathrm{C}$ por 24 horas. Considerou-se a CIM, a menor concentração do extrato que inibiu crescimento bacteriano, ou seja, a menor concentração onde há ausência de crescimento visível. Para melhor visualização do crescimento bacteriano e inibição do mesmo pelo extrato, foi inserido $10 \mu \mathrm{L}$ do corante TTC $(2,3,5$ Cloreto de Trifeniltetrazólio) diluído a 1\%, em cada poço da microplaca.

\section{Determinação da Concentração Bactericida Mínima (CBM)}

Para a determinação da Concentração Bactericida Mínima (CBM), uma alíquota de $10 \mu \mathrm{L}$ foi retirada dos poços com ausência de crescimento e semeados em placas de Petri contendo ágar Mueller-Hinton, as quais foram incubadas a $37^{\circ} \mathrm{C}$ por 24 horas. A CBM foi considerada como a menor concentração na qual o extrato de causou a morte de $99,9 \%$ das células bacterianas em relação ao inoculo inicial na superfície do meio de cultura, ou seja, sem crescimento visível sobre o ágar. Os experimentos formam realizados em triplicata. 


\section{RESULTADOS E DISCUSSÃO}

Os testes evidenciaram que três dos extratos testados possuem ação antibacteriana, sendo eles o EMS, EMF e EES, enquanto o extrato etanólico fresco (EEF) não apresentou atividade (Tabela 1).

O EMS da folha de $M$. linifera apresentou halo de inibição de crescimento contra todas as bactérias Gram-positivas testadas: $S$. aureus ATCC $29213(12,3 \pm 0,05 \mathrm{~mm})$, S. epidermidis $(10,1 \pm 0,1$ $\mathrm{mm}$ ) e E. faecalis (12,6 $\pm 0,0 \mathrm{~mm}$ ) (Tabela 1; Figura 2). Além disso, apresentou CIM de $400 \mu \mathrm{g} / \mathrm{mL}$ para as linhagens de $S$. aureus ATCC 29213, $500 \mu \mathrm{g} /$ $\mathrm{mL}$ para $S$. aureus ATCC 25923, $400 \mu \mathrm{g} / \mathrm{mL}$ para S. epidermidis e $200 \mu \mathrm{g} / \mathrm{mL}$ para a $E$. faecalis. Seu melhor efeito bactericida foi contra o $E$. faecalis, com CBM de $1000 \mu \mathrm{g} / \mathrm{mL}$. (Tabela 1).

Assim como evidenciado em nosso estudo, diversos trabalhos com extratos metanólicos obtidos de espécies da família Araceae também obtiveram resultados promissores com o uso de extratos metanólicos para avaliação da atividade antibacteriana de espécies desta família. Santos et al. (2014) ao avaliar atividade antibacteriana do extrato metanólico de folhas secas de $M$. linifera obteve inibição do crescimento de Aeromonas hydrophila na concentração de $3 \mathrm{mg} /$ cavidade. Kubde et al. (2010) verificaram que extratos metanólicos de Colocasia esculenta (Araceae) apresentaram atividade contra várias bactérias Gram-positivas, com destaque para S. aureus, com CIM de $250 \mu \mathrm{g} / \mathrm{mL}$; entre as bactérias Gramnegativas, destaque foi para o CIM de $500 \mu \mathrm{g} / \mathrm{mL}$ contra Pseudomonas aeruginosa.

Roy et al. (2013) ao utilizar metanol como solvente nos extratos das folhas de Alocasia decipiens (Araceae), obteve CIM de $2 \mu \mathrm{g} / \mathrm{mL}$ para $S$. aureus pelo método de diluição seriada em tubo, e halo de inibição de $16 \mathrm{~mm}$ na concentração de $100 \%$ contra o S. aureus no ensaio de difusão em ágar. Dhanraj et al. (2013) não observaram halo de inibição utilizando extrato metanólico de Colocasia esculenta (Araceae) frente ao S. aureus, mas halo de inibição de $10 \mathrm{~mm}, 10 \mathrm{~mm}$ e $8 \mathrm{~mm}$, contras bactérias Gram-negativas: Salmonella typhi, Klebsiella pneumoniae e Escherichia coli, respectivamente.

EES de M. linifera também se destacou sobre E. faecalis, com CIM de $250 \mu \mathrm{g} / \mathrm{mL}$, evidenciando que a extração de folhas secas possivelmente aumentem as chances de obtenção de moléculas ativas contra bactérias (Tabela 1). Haque et al. (2014), ao avaliar o extrato etanólico de folhas da Alocasia fornicata (Roxb.) observaram inibição em diversas bactérias Gram-positivas, com destaque para S. aureus, onde foi observado halo de inibição de $14 \mathrm{~mm}$ na concentração de $500 \mu \mathrm{g} / \mathrm{disco}$. Ali et al. (2011) relataram que o extrato etanólico de $P$. stratiotes obteve halo de inibição de 25 - $34 \mathrm{~mm}$ frente ao $S$. aureus. Os extratos obtidos da forma fresca (EMF e EEF) foram menos eficientes para esta atividade biológica, sendo que o EMF apresentou CIM de $2.000 \mu \mathrm{g} / \mathrm{mL}$ contra a linhagem $E$. faecalis e, para o EEF, não se observou CIM para todas as linhagens bactérias testadas. O processo de desidratação na obtenção de alguns dos extratos demonstrou ser um dos fatores determinantes na eficácia dos extratos, devido à provável concentração de moléculas com capacidade antimicrobiana.

Apesar da existência de diversos estudos com espécies da família Araceae em relação à atividade antibacteriana, estudos realizando comparação entre a atividade antibacteriana de extratos obtidos de plantas frescas e secas ainda não tinham sido explorados, o que torna o presente estudo inédito. A metodologia utilizada neste trabalho foram também realizadas em espécies de outras famílias, tais como Rodrigues (2008), e Araújo et al. (2014).

Uma CIM inferior a $100 \mu \mathrm{g} / \mathrm{mL}$ apresenta boa atividade antimicrobiana, entre 100 a $500 \mu \mathrm{g} /$ $\mathrm{mL}$ moderadamente ativa e entre 500 e $1000 \mu \mathrm{g} / \mathrm{mL}$ pouco ativa e CIM maior que $1000 \mu \mathrm{g} / \mathrm{mL}$, inativa (Holetz et al., 2002). Desta forma, os resultados obtidos utilizando EMS demostraram que este extrato é moderadamente ativo contra as linhagens S. aureus, S. epidermidis e E. faecalis. -

As variações na atividade antimicrobiana apresentada por extratos de plantas podem ser atribuídas a vários fatores: linhagem utilizada, processo de extração, seja pela diferença dos solventes utilizados ou pelo tipo de material vegetal (fresco ou seco); entre outros fatores (Ostrosky et al., 2008).

Em relação à característica do microorganismo, a partir dos testes de CIM, pode-se inferir que os extratos de $M$. linifera apresentaram ação mais efetiva apenas contra as bactérias Gram-positivas, principalmente através do EMS. Isso se deve provavelmente a estrutura celular diferenciada das bactérias Gram-negativas, pois estas possuem uma parede celular composta de peptideoglicano, e uma membrana externa contendo lipopolissacarídeos, o que Ihes conferem maior proteção contra as substâncias ambientais, extratos de plantas e antibióticos (Askari et al., 2012). Assim como em nosso trabalho, vários estudos também obtiveram resultados melhores contra as bactérias Gram-positivas (Kubde et al., 2010; Ali et al., 2011; Khan et al., 2011; Askari et al., 2012; Rocha, 2013; Roy et al., 2013; Silva et al., 2013; Araújo et al., 2014).

Estudos apontam que o sucesso na extração de substâncias ativas do material vegetal é

Rev. Bras. PI. Med., Campinas, v.17, n.4, supl. III, p.1142-1149, 2015. 
TABELA 1. Concentração inibitória mínima (CIM), concentração bactericida mínima (CBM) e diâmetro dos halos obtidos a partir dos extratos secos (EMS e EES) das folhas de M. linifera.

\begin{tabular}{lcccccc}
\hline \multirow{2}{*}{ Micro-organismos } & \multicolumn{2}{c}{$\mathrm{CIM} \mu \mathrm{g} / \mathrm{mL}$} & \multicolumn{2}{c}{ CBM $\mu \mathrm{g} / \mathrm{mL}$} & \multicolumn{2}{c}{ MDH mm* } \\
\cline { 2 - 6 } $\begin{array}{l}\text { S. aureus } \\
\text { ATCC 29213 }\end{array}$ & 400 & - & 2.000 & - & $12,3 \pm 0,05$ & 0 \\
\hline $\begin{array}{l}\text { S. aureus } \\
\text { ATCC 25923 }\end{array}$ & 500 & - & 2.000 & - & - & 0 \\
$\begin{array}{l}\text { S. epidermidis } \\
\text { ATCC 12228 }\end{array}$ & 400 & - & 2.000 & - & $10,1 \pm 0,1$ & 0 \\
\hline $\begin{array}{l}\text { E. faecalis } \\
\text { ATCC 29212 }\end{array}$ & 200 & 250 & 1.000 & - & $12,6 \pm 0,0$ & 0 \\
\hline
\end{tabular}

*Valores correspondem à média e o desvio padrão do diâmetro dos halos de inibição em mm ( $\mathrm{n}=3)$.

(-) ausência de zona de inibição.

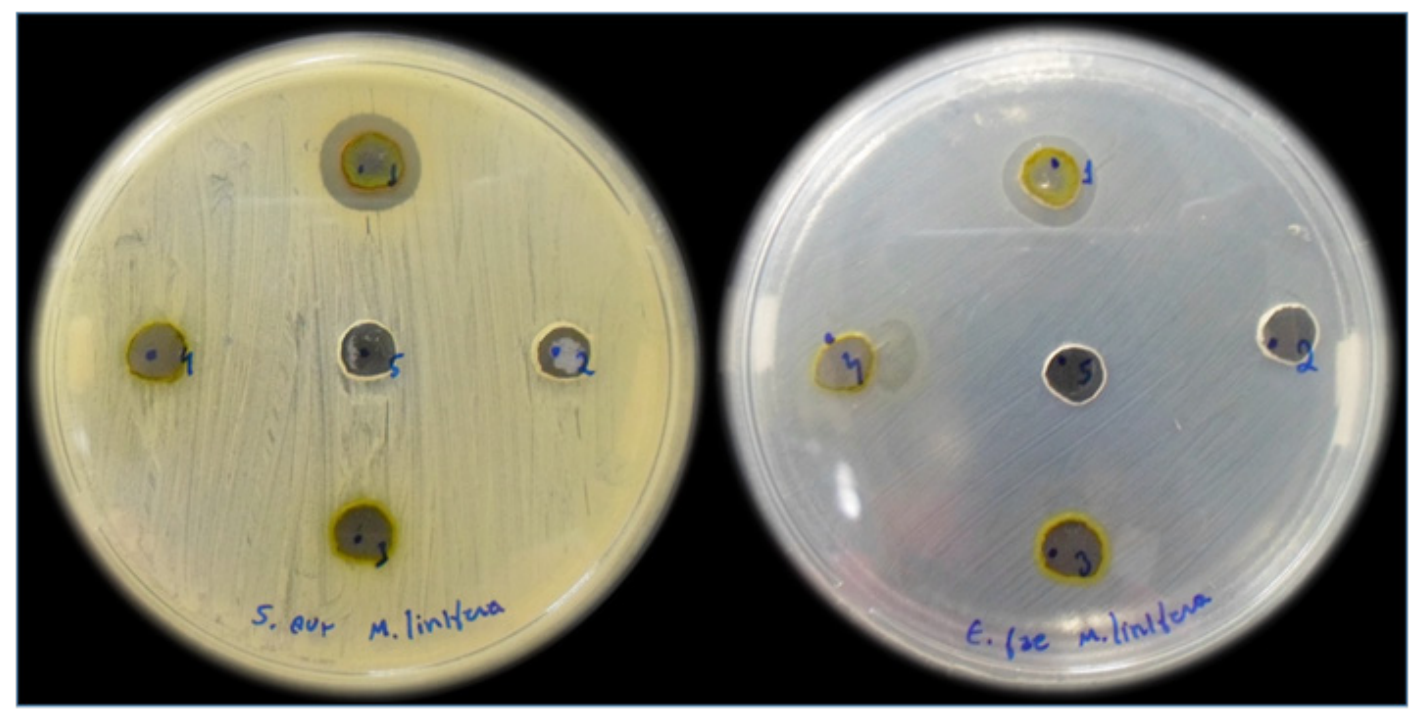

FIGURA 2. Halos de inibição apresentados pela ação de extratos de M. linifera (Arruda) Schott. A- S. aureus ATTC 29213; B- E. faecalis ATCC 29212, e os halos 1, 2, 3, 4, 5 correspondem a EMS, EMF, EES, EEF, Controle Negativo (DMSO), respectivamente.

largamente dependente do tipo de solvente utilizado no processo de extração. Alo et al. (2012), indicou que o etanol e o metanol são melhores solvente que a água, para a extração das substâncias ativas dessas plantas. Assim como Cowan (1999), relatou que quase todas as substâncias ativas identificadas a partir de plantas contra micro-organismos são compostos aromáticos ou orgânicos saturados, estes são mais frequentemente obtidos através de extração inicial com etanol ou metanol. Entre as subtâncias ativas, cabe destaque as antocianinas, terpenóides, saponinas, taninos, flavonas, polifenois. Com isso, foram utilizados neste trabalho os solventes considerados mais eficazes na extração das substâncias ativas das plantas segundo dados da literatura, o metanol e o etanol.

Neste trabalho, o metanol apresentouse melhor solvente de extração em $M$. linifera quando comparado ao etanol. Outros solventes como hexano e acetona, podem ser utilizados com o intuito de extrair outros metabólitos com composição química diferente. Faz-se necessário, portanto, o isolamento dos compostos majoritários contidos no extrato de folhas da $M$. linifera para que se possa descobrir qual o composto possui a atividade bacteriana, já que extratos brutos é uma mistura de vários compostos contidos nas folhas, acarretando na grande maioria das vezes na inibição ou diminuição do efeito antibacteriano do verdadeiro composto detentor de atividade antibacteriana. Além de se observar que moléculas isoladas tendem a apresentar efeitos biológicos bem melhores, pois ocorre intensificação do efeito (Rocha, 2013).

\section{CONCLUSÃO}

Os extratos metanólicos seco (EMS), metanólico fresco (EMF) e etanólico seco (EES) das folhas de Montrichadia linifera apresentaram atividade antibacteriana contra bactérias Gram- 
positivas testadas, sendo que o EMS foi o que apresentou o resultado mais significativo.

Futuros estudos serão necessários para se testar frações desses extratos, além da determinação de seus constituintes químicos, o que possibilitaria resultados antimicrobianos ainda mais promissores.

\section{AGRADECIMENTOS}

Os autores agradecem ao Conselho Nacional de Desenvolvimento Científico e Tecnológico (CNPq) por dar suporte financeiro ao projeto Biodiversidade de Macrófitas Aquáticas do Delta do Parnaíba (Número do Projeto 5034942009-7), que incluiu bolsa de produtividade a I. M. Andrade e bolsa de iniciação científica PIBIC; aos Sistemas de Autorização e Informação em Biodiversidade (ICMBio-SISBIO) pela autorização da coleta de material botânico para o estudo.

\section{REFERÊNCIAS}

ALI, K.M. et al. Cytotoxicity, Antimicrobial and Neuropharmacological evaluation of ethanolic extract of Pistia stratiotes L. International Research Journal of Pharmacy, v.2, n.2, p.82-92, 2011.

ALO, M.N. et al. Antibacterial activity of water, ethanol and methanol extracts of Ocimum gratissimum, Vernonia amygdalina and Aframomum melegueta. Advances in Applied Science Research, v.3, n. 2, p.844-48, 2012.

AMARANTE, C.B. et al. Composição química e valor nutricional para grandes herbívoros das folhas e frutos de aninga (Montrichardia linifera, Araceae). Acta Amazonica, v.40, n.4, p.729-73. 2010.

AMARANTE, C.B. et al. Avaliação da composição mineral do chá da folha senescente de Montrichardia linifera (Arruda) Schott (Araceae) por Espectrometria de Absorção Atômica com Chama (FAAS). Quimíca Nova, v.34, n.3, p.419-23, 2011a.

AMARANTE, C.B. et al. Caracterização física, química e nutricional dos frutos da aninga. Planta Daninha, v.29, n.2, p.295-303, 2011b.

AMOROZO, C.M.; GELY, A. Uso de plantas medicinais por cablocos do baixo amazonas, Barcarena - PA, Brasil. Boletim Museu Pará Emilio Goeldi. Serie Botânica, v.4, n.1, p.47-131, 1988.

ARAÚJO, K.M. et al. Identification of Phenolic Compounds and Evaluation of Antioxidant and Antimicrobial Properties of Euphorbia Tirucalli L.. Antioxidants, v.3, p.159-75, 2014.

ASKARI, G.A. et al. Evaluation of Antimicrobial Activity of Aqueous and Ethanolic Extracts of Leaves of Vitis vinifera Collected from Different Regions in Morocco. American-Eurasian Journal of Agricultural \& Environmental Sciences. v.12, n.1, p.85-90, 2012.

BETTEGA, P.V.C. et al. Fitoterapia: dos canteiros ao balcão da farmácia. Archives of Oral Research, v.7, n.1, p.89-97, 2011.

BRUNING, M.C.R. et al. A utilização da fitoterapia e de plantas medicinais em unidades básicas de saúde nos municípios de Cascavel e Foz do Iguaçu - Paraná: a visão dos profissionais de saúde. Revista Ciência \& Saúde Coletiva, v.17, n.10, p.2675-85, 2012.

CLSI. Methods for Dilution Antimicrobial Susceptibility Tests for Bacteria that Grow Aerobically. 6.ed. Wayne, PA, USA: National Committee for Clinical Laboratory Standards, 2003a.

CLSI. Performance Standards for Antimicrobial Disk Susceptibility Tests. 8.ed. Wayne, PA, USA: National Committee for Clinical Laboratory Standards, 2003b.

COELHO, M.A.N. Montrichardia in Lista de Espécies da Flora do Brasil. Jardim Botânico do Rio de Janeiro. Disponível em <http://floradobrasil.jbrj.gov.br/jabot/ floradobrasil/FB5014>. Acesso em: 04 ago. 2013.

COWAN, M.M. Plant Products as Antimicrobial Agents. Clinical microbiology reviews, v.12, n.4, p.564-82, 1999.

DASH, B.K. et al. Antibacterial Activities of Methanol and Acetone Extracts of Fenugreek (Trigonella foenum) and Coriander (Coriandrum sativum). Life Sciences and Medicine Research, v.2011, n.27, p.1-8, 2011.

DHANRAJ, N.B. et al. Phytochemical screening and antibacterial activity of Western Region wild leaf Colocasia esculenta. International Research Journal of Biological Sciences, v.2, n.10, p.18-21, 2013.

FEIJÓ, A.M. et al. Plantas medicinais utilizadas por idosos com diagnóstico de Diabetes mellitus no tratamento dos sintomas da doença. Revista Brasileira de Plantas Medicinais, v.14, n.1, p.50-56, 2012.

FIDALGO, O.; BONONI, V.L.R. Técnicas de coleta, preservação e herborização de material botânico. São Paulo: Instituto de Botânica, 1989. 62p.

$\mathrm{HAIGH}$, A. et al. Interactive web-taxonomy for the Araceae. Blumea, v.54, n.1-3, p.13-5, 2009.

HAQUE, M. et al. Antibacterial and Cytotoxic Activities of Alocasia fornicata (Roxb.). International Journal of Nutrition, Pharmacology, Neurological Diseases, v.4, n.1, p.29-33, 2014.

HOLETZ, F.B. et al. Screening of some plants used in the Brazilian folk medicine for the treatment of infectious diseases. Memorias do Instituto Oswaldo Cruz, v.97, p.1027-31, 2002.

KHAN, M.A.A. et al. Cytotoxicity, antimicrobial and neuropharmacological, evoluation of ethanolic extract of Pistia stratiotes. Internation Research Journal of Pharmacy, v.2, n.2, p.82- 92, 2011.

KUBDE, M.S. et al. In vitro antimicrobial activity of the crude extracts of Colocasia esculenta leaves (Araceae). International Journal of Pharmaceutical Sciences and Research, v.1, n.8, p.88-91, 2010.

LINS, A.L.F.A. Aspectos morfológicos e anatômicos de raízes do gênero Montrichardia Crüger. (Araceae). 1994. Dissertação (Mestrado - Área de Concentração em Botânica). Universidade Federal do Rio Grande do Sul, Porto Alegre.

LOPES, G.A.D. et al. Plantas medicinais: indicação popular de uso no tratamento de hipertensão arterial sistêmica (HAS). Revista Ciência em Extensão, v.6, n.2, p.143-55, 2010.

MAIA-ARAÚJO, Y.L.F. et al. Comparação entre duas técnicas utilizadas no teste de sensibilidade antibacteriana do extrato hidroalcoólico de própolis vermelha. Scientia Plena, v.7, n.4, p.1-4, 2011.

Rev. Bras. PI. Med., Campinas, v.17, n.4, supl. III, p.1142-1149, 2015. 
MARTINS, A.G. et al. Levantamento etnobotânico de plantas medicinais, alimentares e tóxicas da Ilha do Combu, Município de Belém, Estado do Pará, Brasil. Sociedade Brasileira de Farmacognosia, v.86, n.1, p.21-30, 2005.

MAYO, S.J. et al. The General of Araceae. Kew: Royal Botanic Gardens, 1997.

MEDINA, J.C. Plantas fibrosas da flora mundial. Campinas: Instituto Agronômico, 1959.

OSTROSKY, E.A. et al. Métodos para avaliação da atividade antimicrobiana e determinação da concentração mínima inibitória $(\mathrm{CMI})$ de plantas medicinais. Revista Brasileira de Farmacognosia, v.16, n.2, p.301-07, 2008.

PAREKH, J. et al. Efficacy of Aqueous and Methanol Extracts of Some Medicinal Plants for Potential Antibacterial Activity. Turkish Journal of Biology, v.29, p.203-10, 2005.

PEREIRA, R.J.; CARDOSO, M.G. Metabólitos secundários vegetais e benefícios antioxidantes. Journal of Biotechnology and Biodiversity, v.3, n.4, p. 146-52, 2012.

PLOWMAN, T. Folk uses of new world aroids. Economic Botany, v.23, p.97-122, 1969.

PULLE, A. A.; LANJOUW, J. Flora do Suriname Part. 2. Leiden: E. J. Brill, 1968.

ROCHA, J.A. Variabilidade Genética e Avaliação Antibacteriana e Anti-Schistosoma dos alcaloides Pilosina, Epiisopilosina, Isopilosina e Macaubina de Jaborandi (Pilocarpus microphyllus Stapf ex Wardlew.). 2013. 146p. Dissertação (Mestrado - Área de concentração em Biotecnologia). Universidade Federal do Piauí, Parnaíba.

RODRIGUES, C.G. Atividade antibacteriana de taninos extraídos de folhas de Psidium guineense Sw. (Myrtaceae). 2008. 73p. Dissertação (Mestrado - Área de Concentração em Ciências Biológicas). Universidade Estadual de Montes Claros, Montes Claros.

ROY, S. et al. In Vitro antibacterial activity of Alocasia decipiens Schott. International Journal of Pharmacy and Pharmaceutical Sciences, v.5, n.1, p.155-57, 2013.

SANTOS, A.P.B. A beleza, a popularidade, a toxicidade e a importância econômica de espécies de Aráceas. Revista Virtual de Química, v.3, p.181-95, 2011.

SANTOS, M.M. et al. Uso empírico de plantas medicinais para tratamento de diabetes. Revista Brasileira de Plantas Medicinais, v.14, n.2, p.327-34, 2012.

SANTOS, F.N. et al. Montrichardia linifera (Araceae) biological potential, phytochemical prospection and polyphenol contente. Universitas Scientiarum, v.19, n.3, p.213-24, 2014.

SASWATI, R. et al. Antibacterial activity of Araceae: an overview. International Journal of Research in Ayurveda and Pharmacy, v.4, n.1, p.15-17, 2013.

SILVA, M.F.S. et al. Geometric morphometrics of leaf blade shape in Montrichardia linifera (Araceae) populations from the Rio Parnaíba Delta, north-east Brazil. Botanical Journal of the Linnean Society, v.170, p.554-72, 2012.

SILVA, J.V.S. et al. Uma revisão bibliográfica sobre Araceae com foco nos gêneros Pistia, Philodendron e Montrichardia: aspectos botânicos, fitoquímicos e atividades biológicas. Revista Fitos, v.8, n.2, p. 73160, 2013.

SOUSA, F.C. et al. Uso de plantas medicinais (fitoterápicos) por mulheres da cidade de Icó-CE. Revista Brasileira de Biologia e Farmácia, v.5, n.1, p.161-70, 2011. 